\title{
Behavioral Risk Factors of Hypertension among Pastoral and Agro Pastoral Adult Communities, Eastern Ethiopia, Somali Regional State, 2016
}

\section{Wubareg Seifu*, Mohamed Hussein, Muhumed Ibrahim and Ali Sigale}

College of Medicine and Health Sciences, Public Health Department, Jigjiga University, Jigjiga, Ethiopia

*Corresponding author: Seifu W, Lecturer of Public Health, College of Medicine and Health Sciences, Jigjiga University, Jigjiga, Ethiopia, Tel: +251-920981050; E-mail: wub2003@gmail.com

Received date: January 09, 2017; Accepted date: March 21, 2017; Published date: March 30, 2017

Copyright: (c) 2017 Seifu W, et al. This is an open-access article distributed under the terms of the Creative Commons Attribution License, which permits unrestricted use, distribution, and reproduction in any medium, provided the original author and source are credited.

\section{Abstract}

Background: Hypertension is a growing public health problem in many developing countries including Ethiopia. However, its prevention and control has not yet received due attention. The overall objective of the study was to assess prevalence of behavioral risk factors of hypertension among adults in Jigjig town, Somali region state, Eastern Ethiopia, from May to June, 2016.

Materials and methods: A community based cross sectional study was conducted from May to June 2016 among 330 adults of 20 years old and above residing in Jigjiga town using multistage sampling technique. Data were collected through face to face interview after verbal informed consent was taken. Additionally physical measurements such as blood pressure, weight and height of the participants were measured following standard procedures. Odds ratio with $95 \%$ confidence interval was estimated using multivariable logistic regression to identify independent predictors of hypertension.

Result: The overall prevalence of hypertension was 13.3\% (95\% Cl: 10.90-15.70). Among all hypertensive people identified, $12(28.57 \%)$ were newly screened. Family history of hypertension [AOR: 25.0 (11.65 - 98.12)], individuals who did not engaged in any kind physical activity [AOR: 16.24 (2.12 - 99.12)] and Khat chewers [AOR: 1.98 (2.987 - 5.456)] were behavioral risk factors associated with hypertension.

Conclusion: There was a high prevalence of hypertension probably indicating a hidden epidemic in this community. Family history of hypertension, Khat chewing and physical inactivity was behavioral factors associated with hypertension in this study. Hence launching a strategy to screen at least adults visiting health institutions for other reasons is paramount to identify new cases. As well health education on hypertension risk reduction should be done by promoting healthy life styles such as regular physical exercise and avoiding khat chewing.

Keywords: Hypertension; Prevalence; Behavioral risk factors; Jigjiga town

\section{Introduction}

Hypertension is defined as arterial blood pressure that exceeds $140 / 90 \mathrm{mmHg}$ at several determination. Hypertension is a major contributor to the growing global pandemic of cardiovascular disease and stroke. It is behind only under nutrition and unsafe sex in its contribution to the burden of disease worldwide. Globally, about $62 \%$ of cerebrovascular diseases and $49 \%$ of ischemic heart disease are attributable to elevated blood pressure (BP) that could have been reduced by antihypertensive drug therapy $[1,2]$. Raised blood pressure is estimated to cause 7.5 million (12.8\% of all causes of death) deaths per year. Hypertension (HTN) doubles the risk of cardiovascular diseases such as coronary heart disease $(\mathrm{CHD})$, congestive heart failure $(\mathrm{CHF})$, stroke, renal failure and peripheral arterial disease $[2,3]$.

Though data on magnitude of the problem is limited in Sub Saharan Africa (SSA), a systemic review of Seventeen studies pertaining to eleven countries revealed that prevalence rate of hypertension in SSA in 2008 was at $16.2 \%$ [ $95 \%$ confidence interval (CI) $14.1-20.3$ ], ranging from $10.6 \%$ in Ethiopia to $26.9 \%$ in Ghana. The total number of hypertensive in SSA was estimated at 75 million in 2008 and at 125.5 million by 2025 [4]. According to Global burden of hypertension analysis of worldwide data indicated that more than a quarter of the world's adult population totaling nearly one billion $26.4 \%$ had HTN. The rapid rise in the mortality of cardiovascular disease over a fairly short period is attributable mainly due to changes in life style changes such as diet and physical activity [5].

Ethiopia is a country currently prioritizing prevention of communicable and nutritional deficiency diseases. However it experiencing double mortality burden as evidenced among adult population in Addis Ababa [6]. In addition a study conducted in Gondar by 2012 among 679 subjects aged above 35 years resulted $28 \%$ [7] of prevalence of HTN whereas done in Addis Ababa in 2010 on 1935 subjects of working age reported higher prevalence in men $22 \%$ than among women $14.9 \%$ [8]. In Ethiopia, a cross sectional study conducted in Mekelle town in 2013, indicated $11 \%$ of subjects were hypertensive [9]. A study conducted on The Double Mortality Burden among Adults in Addis Ababa, Ethiopia, in 2006-2009, revealed that the leading cause of death was cardio vascular disease (CVD) (24\%); 
proportions for hypertension (12\%) and stroke (11\%) were similar and constituted most of the CVD deaths [10].

The current status of hypertension is neither explicitly clear nor formally quantified in the Ethiopian Somali regional state specifically in this study area due to the absence of researches conducted in this area. However, reports from health institutions indicated that the presence of increased trend of hypertensive cases and almost the disease is climbing top ward to rank the eighth of the top ten diseases of causing morbidity and hospital admission in the study areas [11], and also the information about risk factors associated with this disease is not yet examined in these particular area. Therefore this study was conducted to determine prevalence and to identify risk factors associated with hypertension among adults in Jigjiga town. Based on this information intervention towards combating chronic non communicable diseases particularly hypertension can be designed by stakeholders accordingly.

\section{Methodology}

\section{Study setting}

The study was conducted in Jigjig town Ethiopian Somali regional state which is located at a distance of 636 kilometers away from the capital city Addis-Ababa, in the Eastern part of Ethiopia. The health service coverage of Jigjig town is estimated to be $85 \%$ and existing health facilities are 2 regional hospitals, 2 private hospitals, 2 functional health centers, 2 mother and child health clinic and 27 private clinics and 10 health posts. The total adult population ( $>20$ years) are 62,633 (33,758 are males and 28,875 are females) [12].

\section{Study design and participants}

A community based cross sectional quantitative study was conducted among randomly selected adult population who were 20 years and above in Jigjiga town from May to June 2016. The sample size was determined using a single population proportion formula with the following assumption: Prevalence of hypertension to be $11.0 \%$ [9], margin of sampling error tolerated - 5\% (0.05), critical value at $95 \%$ confidence interval of certainty (1.96), a design effect of 2 and $10 \%$ for nonresponse making the final sample size of 330 adult population.

The study participants were selected through multi-stage sampling technique. There are 12 kebeles in Jigjiga town and from these three kebeles were selected by simple random sampling techniques. Then the calculated sample size of 330 was proportionally allocated to the selected kebeles. Each study participants were selected and interviewed every two intervals which were determined by statistical formula until the desired sample size was achieved for the respective kebeles [13-17]. In cases where there is more than one eligible individual in the selected household, a lottery method was used where as if there is no eligible person in the selected household the next household was visited accordingly.

\section{Measurements}

Data were collected according to the WHO-STEP wise approach recommendation for chronic diseases risk factor surveillance which involves survey questionnaires for step I and simple physical body measurements for step II and biochemical tests for step III [18].

Participants were with lightweight wears and barefooted during measuring their weight and height. Electronic scales (Seca Gmbh,
Hamburg, Germany) were placed at flat surface to measure weight (to the nearest 10 grams). Height was measured using portable stadiometer (to the nearest $0.1 \mathrm{~cm}$ ).

Blood pressure was measured using digital blood pressure measurement devices (Omron M3). Blood pressure was measured and recorded during household visits following the STEPS methods (at the right arm at heart level after a period of 5 minutes of rest with no smoking or caffeine allowed for 30 minutes before measurement). The averages of the last two measurements, from the three readings, were used in the analysis.

In this study hypertension was defined as self-reported use of antihypertensive medication within the past 2 weeks or an average systolic $\mathrm{BP} \geq 140 \mathrm{mmHg}$, an average diastolic $\mathrm{BP} \geq 90 \mathrm{mmHg}$, or both. Body mass index (BMI) is calculated using the formula, the weight in kilograms divided by the square of the height in meters $\left(\mathrm{kg} / \mathrm{m}^{2}\right)$. Categories of BMI were done based on World Health Organization (WHO) classification as: <18 (underweight), 18.5-24.9 (Healthy weight), 25-29.9 (overweight) and $\geq 30$ (obese).

Data collectors were given three day training on the questionnaires, interviewing and physical measurement techniques. The questionnaires were initially prepared in English and then have been translated into the local language, Somaligna and again it was translated back into English to check its consistency. The questionnaires were pre-tested before the actual data collection. Additional modifications were made to the questionnaire in terms of in terminologies and formatting based on the pretest findings. The supervisors checked each completed questionnaire and principal investigator monitored the overall quality of the data collection.

Quantitative data were cleaned, edited, and entered onto Epidata version 3.2 and exported to SPSS version 20 statistical software for analysis. Frequency distribution and cross tabulation were done against the variables of interest. Bivariate analyses were done to assess the association between explanatory variables and outcome variable of the study. All variables with a p-value of $<0.2$ at the bivariate analysis were included into multivariable logistic regression model in which odds ratio with $95 \%$ confidence intervals were estimated to identify independent predictors of hypertension. P-values less or equal to 0.05 were employed to declare the statistical significance.

The study was cleared from the ethical review board of Jigjiga University college of Medicine and Health sciences. The interviewees have also been well informed about the aim of the study. Additionally verbal consent was secured from each study participants. Finally, confidentiality was ascertained by justifying that no information was disclosed individually without the full willingness of the respondent. Study participants who were found as HTN were linked to the nearby health facility for further medical services.

\section{Results}

A total of 330 adults aged 20 years and older from three kebeles of Jigjiga town were included in this study with $100 \%$ response rate.

Age of the participants ranged from 20-83 years while 142 (43\%) were between the age of 20-29 with the mean age of $35.33 \pm 2.14$ years. Majority 316 (95.75\%) were Muslim and Somali ethnics 303 (91.8\%).

Nearly half 172 (52.12\%) were married and about one third 57 $(17.27 \%)$ were housewives as shown in Table 1 below. 
Citation: Seifu W, Hussein M, Ibrahim M, Sigale A (2017) Behavioral Risk Factors of Hypertension among Pastoral and Agro Pastoral Adult Communities, Eastern Ethiopia, Somali Regional State, 2016. J Trop Dis 5: 234. doi:10.4172/2329-891X.1000234

Page 3 of 6

\begin{tabular}{|c|c|c|c|c|c|}
\hline Characteristics & Frequency & Percent & Protestant & 3 & 0.91 \\
\hline Sex & & & Others & 2 & 0.61 \\
\hline Male & 156 & 47.28 & Ethnicity & & \\
\hline Female & 174 & 52.72 & Somali & 303 & 91.81 \\
\hline Age & & & Amhara & 7 & $2.1 \%$ \\
\hline $20-29$ & 142 & 43 & Oromo & 13 & 3.94 \\
\hline $30-39$ & 78 & 23.64 & Gurage & 3 & 0.91 \\
\hline $40-49$ & 56 & 16.97 & Tigre & 1 & 0.30 \\
\hline $50-59$ & 30 & 9.0 & Harari & 3 & 0.90 \\
\hline
\end{tabular}

Table 1: Socio demographic characteristics of study participants, Jigjiga town, Ethiopia, Somali regional state, june 2016.

Twenty nine participants $(8.8 \%)$ declared that they were smoking cigarettes previously. One hundred eleven participants (33.63\%) were current smokers of whom $12(10.8 \%)$ were hypertensive patients. One from every five participants $(20.95 \%)$ was involved in vigorous activities such as carrying or lifting heavy loads and construction works. Most participants $276(83.6 \%)$ use to walk for at least 10 minutes continuously every day. More than two quarters 212 (64.24\%) of the participants reported using vehicles as main mode of transportation to their work places. The mean body mass index (BMI) of the respondents was $23.35( \pm 4.02 \mathrm{SD}) \mathrm{kg} / \mathrm{m}^{2}$ whereas $90(43.18 \%)$ of the respondents were overweight while $13.63 \%$ were obese.

More than three quarters 268 (81.21\%) of respondents reported that they usually use vegetable oil for meal preparation while 193 (58.5\%) reported eating vegetables at least 4-7 days in a week. Twenty three (7\%) respondents have reported excessive use of salt than other family members. Almost all 303 (91.81\%) of the study participants were current khat chewers.

The mean systolic and diastolic BP results were $120.2 \mathrm{mmHg}( \pm 19.6$ $\mathrm{SD})$ and $72.4 \mathrm{mmHg}( \pm 10.5 \mathrm{SD})$. The overall prevalence of hypertension was $13.3 \%$ (95\% CI: 10.9-15.7), slightly lower in men $(10.9 \%)$ than women $(15.7 \%)$ though the difference was not statistically significant $\left(\mathrm{X}^{2}=1.57, \mathrm{P}=0.211\right)$. among all hypertensive people identified, $12(28.57 \%)$ did not know they had hypertension (newly screened).

In the multivariable logistic regression analysis, family histories of hypertension [AOR: 25 CI: (11.65 - 98.123)] and level physical activity [AOR: 16.2423, CI: $(2.198$ - 99.120)] were the independent predictors of hypertension among adults 20 years old and above as shown in Table 2 below. 
Citation: Seifu W, Hussein M, Ibrahim M, Sigale A (2017) Behavioral Risk Factors of Hypertension among Pastoral and Agro Pastoral Adult Communities, Eastern Ethiopia, Somali Regional State, 2016. J Trop Dis 5: 234. doi:10.4172/2329-891X.1000234

Page 4 of 6

\begin{tabular}{|c|c|c|c|c|}
\hline $40-49$ & 5 & 51 & $0.5649(0.2019-1.5803)$ & $0.4(0.2-1.023)$ \\
\hline $50-59$ & 6 & 24 & $1.4405(0.526-3.945)$ & $0.745(0.317-2.745)$ \\
\hline$>60$ & 4 & 20 & $1.1524(0.3579-3.7102)$ & $0.84(0.3-2.602)$ \\
\hline \multicolumn{5}{|l|}{ Education level } \\
\hline No formal education & 11 & 90 & 1 & 1 \\
\hline Primary level & 6 & 18 & $2.7273(0.8934-8.3259)$ & $1.455(0.654-6.89)$ \\
\hline Secondary level & 9 & 66 & $1.1157(0.4374-2.8461)$ & $0.768(0.216-1.75)$ \\
\hline College/University & 15 & 108 & $1.1364(0.4971-2.5977)$ & $0.754(0.231-1.97)$ \\
\hline Postgraduate & 3 & 4 & 6.1364 ( $1.2112-31.0885)$ & $4.521(0.54-25.12$ \\
\hline \multicolumn{5}{|l|}{ Occupation } \\
\hline Government employed & 6 & 65 & 1 & 1 \\
\hline Merchant & 10 & 79 & $1.3713(0.4732-3.9741)$ & $0.67(0.2187-2.656)$ \\
\hline Daily laborer & 4 & 39 & $1.1111(0.295-4.1844)$ & $0.4675(0.187-2.435)$ \\
\hline House wife & 8 & 49 & $1.7687(0.5762-5.4295)$ & $1.05(0.214-4.87)$ \\
\hline Unemployed & 11 & 15 & $7.9444(2.5351-24.8961)$ & $6.314(1.451-18.7632)$ \\
\hline Farmer & 5 & 39 & $1.0833(0.2536-4.6271)$ & $0.756(0.132-3.43)$ \\
\hline \multicolumn{5}{|l|}{ BMI } \\
\hline Normal & 15 & 77 & 1 & 1 \\
\hline Underweight & 4 & 114 & $0.1801(0.0576-0.5633)$ & $0.087(0.0097-0.324)$ \\
\hline Overweight & 19 & 73 & $1.3361(0.6318-2.8253)$ & $0.87(0.435-1.54)$ \\
\hline Obese & 6 & 22 & $1.4(0.4857-4.0357)$ & $0.86(0.234-2.076)$ \\
\hline \multicolumn{5}{|l|}{ Khat chewing habit } \\
\hline Yes & 273 & 30 & $2.875(1.3497-6.124)$ & $1.98(2.987-5.456)^{*}$ \\
\hline No & 12 & 15 & 1 & 1 \\
\hline \multicolumn{5}{|c|}{ Family history of hypertension } \\
\hline Yes & 19 & 8 & $45.6(17.1893-120.9682)$ & $25(11.65-98.123)^{*}$ \\
\hline No & 15 & 288 & 1 & 1 \\
\hline \multicolumn{5}{|l|}{ Walking status } \\
\hline None & 8 & 2 & $21.1429(3.6834-121.3605)$ & $16.24(2.198-99.120)^{*}$ \\
\hline Daily & 29 & 247 & $0.6206(0.2536-1.5185)$ & $0.4209(0.189-0.546)$ \\
\hline$<$ daily/week & 7 & 37 & 1 & 1 \\
\hline
\end{tabular}

Table 2: Bivariate and multivariate logistic regression analysis of factors associated with hypertension among study participants in Jigjiga town, Ethiopia, Ethiopian Somali Region, June 2016.

\section{Discussion}

This study attempted to determine the prevalence and associated factors of hypertension among adult population. The overall prevalence of hypertension was $13.3 \%$ (95\% CI: 10.90-15.70) which is slightly lower in men (10.9\%) than women (15.7\%). In the multivariate analysis family history of hypertension [AOR: 25.0 (11.65 - 98.12)], individual who did not engaged in any kind physical activity [AOR: $16.24(2.12$ - 99.12)] and khat chewers [AOR: 1.98 (2.987-5.456] were independent predictors of hypertension. 
Page 5 of 6

Slightly more than one in every seven adults aged 30 years or older had hypertension in Jigjiga town (13.3\%). This result was comparable with a community based study conducted in Mekelle town, $11 \%$ [9]. This prevalence estimate in this study is much lower than those reported from most urban communities of Sub-Saharan Africa (23.7-33.3\%), Gondar (28.3\%), Addis Ababa (30\%), and South Ethiopia (16.9\%) $[4,7,10,13]$ respectively. This discrepancy may be explained in two ways; First, the age difference in the study populations ( $>20$ years in our case while in other studies age of participants ranges between 25-65 years). Most (43\%) of our study population lies in the age range of 20-29 in which the HTN prevalence is expected be low. On top of this genetic difference which could probably affect blood pressure. However when we calculate the age specific proportion of HTN it is comparable with Gondar, South Ethiopia and Addis Ababa $[4,7,10]$.

About $71.43 \%$ of hypertension patients are aware of their hypertension status. However, $28.57 \%$ of hypertension patients are unaware of the condition. This finding is in agreement with other similar studies, where by $37 \%$ and $44.8 \%[13,14]$ of hypertension patients did not know their status. This supports the notion that hypertension is a silent killer which did not magnificent unless others wise reach to the sever stage. In multivariate analysis family history of hypertension [AOR: $25.0(11.65$ - 98.12)] is positively associated with HTN in the studied community which comparable with this studies [15-17]. Walking for at least ten minutes continuously every day was negatively associated with hypertension. Individual who did not engaged in any kind physical activity [AOR: $16.24(2.12$ - 99.12)] were at higher risk of developing HTN. This finding is in accordance with other similar studies $[7,14,17]$. Khat chewer individuals were 2 times [AOR: 1.98 (2.987 - 5.456)] more like to be hypertensive as compared their counterparts which is comparable with studies $[19,20]$ conducted in different time. Since khat chewing leads to the secretion of vasoconstrictor chemical such as epinephrine and nor epinephrine. We believe that the findings of our study will contribute to efforts made to tackle hypertension in Ethiopia. However, there are certain limitations worth mentioning. Assessment of behavioral risk factors such as smoking, alcohol intake and khat chewing were based only history of use without assessment of amount and duration of use. As a result cause effect relationship could not be ascertained. This study is also limited to behavioral and physical measurements, and did not include biochemical measurements.

\section{Conclusions and Recommendations}

This study showed that the prevalence of hypertension among a sample of the adult population in Jigiga town was 44 (13.3\%). Among all hypertensive people identified 12 (28.57) did not know that they had the disease during the survey (newly screened). The study indicated that positive family history, Khat chewing and inadequate physical activity were significantly associated with hypertension. Health information dissemination on the importance of avoiding khat chewing, regular physical activity, regular checkup, launching opportunistic screening programs for adults to identify new cases, and expanding community based education programs focusing on risk factors of chronic non communicable diseases should designed to combat HTN in the studied community. Additionally conducting a study with strong design which addresses the biochemical risk factors of hypertension is also more important for comprehensive services.

\section{Competing Interests}

We authors declare that we have no competing interests regarding the publication of the paper.

\section{Authors' Contributions}

Wubareg Seifu conceived the research topic. Wubareg Seifu, Mohamed Hussein, Muhumed Ibrahim and Ali Sigale contributed to the development of the research proposal, analysis, and interpretation of the data. Wubareg Seifu coordinated the data collection and drafted the manuscript. Mohamed Hussein, Muhumed Ibrahim and Ali Sigale participated in the review of the manuscript. All authors read and approved the manuscript for publication.

\section{Acknowledgment}

We would like to express our deepest gratitude to Jigjiga University for budgetary support. We are also extremely grateful for data collectors, supervisors and study communities.

\section{References}

1. WHO (2011) Global status report on non-communicable disease 2010. World Health Organization, Geneva, Switzerland.

2. Ezzati M, Lopez AD, Rodgers A, VanderHoorn S, Murray CJL (2003) The comparative risk assessment collaborating group selected major risk factors and global and regional burden of disease. Lancet 360: 1347-1360.

3. Kotcher T (2008) Harrison's Principles of internal medicine. In: Thonys F, Eugene B, Dennis K (eds). Hypertensive vascular disease. Mc Graw-Hill Companies, USA. pp: 1549-1562.

4. Twagirumukiza M, DeBacquer D, Kips JG, Backer G, Stichele RV, et al. (2011) Current and projected prevalence of arterial hypertension in subSaharan Africa by sex, age and habitat: An estimate from population studies. J Hypertens 29: 1243-1252.

5. Kearney P, Whelton M, Reynolds K, Muntner P, Whelton P, et al. (2005) Global burden of hypertension: Analysis of worldwide data. Lancet 365: 217-223.

6. Tesfaye F, Byass P, Wall S (2009) Population based prevalence of high blood pressure among adults in Addis Ababa: Uncovering a silent epidemic. BMC Cardiovasc Disord 9: 32-39.

7. Awoke A, Awoke T, Alemu S, Megabiaw B (2012) Prevalence and associated factors of hypertension among adults in Gondar, Northwest Ethiopia: a community based cross-sectional study. BMC Cardiovasc Disord 12: 111-113.

8. Tran A, Gelaye B, Girma B, Lemma S, Berhane Y, et al. (2011) Prevalence of metabolic syndrome among working adults in Ethiopia. International Journal of Hypertension.

9. Assefa BZ, Haftu BG, Alemayehu BK (2014) Prevalence and associated factors of hypertension among adult population in Mekelle city, Northern Ethiopia. IJIPSR 2: 653-668.

10. Misganaw A, Mariam DH, Araya T (2012) The double mortality burden among adults in Addis Ababa, Ethiopia. Prev Chronic Dis 9: 110142.

11. No Authors Listed (2015) Karamara General Hospital annual report, Jigjiga.

12. (2011) Central Statistical Agency, Ethiopian and Demographic Survey, Addis Ababa.

13. Bonsa F, Gudina EK, Hajito KW (2014) Prevalence of hypertension and associated factors in Bedele Town, Southwest Ethiopia. Ethiop J Health Sci 24: 21-26.

14. Helelo TP, Gelaw YA, Adane AA (2014) Prevalence and associated factors of hypertension among adults in Durame Town, Southern Ethiopia. PLOS one 9: 11-14. 
Citation: Seifu W, Hussein M, Ibrahim M, Sigale A (2017) Behavioral Risk Factors of Hypertension among Pastoral and Agro Pastoral Adult Communities, Eastern Ethiopia, Somali Regional State, 2016. J Trop Dis 5: 234. doi:10.4172/2329-891X.1000234

Page 6 of 6

15. Gebreselassie KZ, Padyab M (2014) Epidemiology of hypertension stages in two countries in Sub-Sahara Africa: Factors associated with hypertension stages. Int J Hypertens 9: 592-596.

16. World Health Organization (2013) A global brief on hypertension silent killer, global public health crisis.

17. Meshram II, Laxmaiah A, Mallikharjun RK (2014) Prevalence of hypertension and its correlates among adult tribal population (\$20 years) of Maharashtra state, India. Int J Health Sci Res 4: 130-139.
18. WHO (2015) Stepwise approach to surveillance (STEPS). World Health Organization, Geneva, Switzerland.

19. Andualem M, Hassen T, Yimane T (2001) Effect of Khat (Catha edulis Forsk) on blood pressure and heart rate in Jimma Town, Ethiopian. J Health Dev 16: 325-334.

20. Bizuayehu W, Muluken B (2013) The effect of khat (Catha edulis) chewing on blood pressure among male adult chewers, Bahir Dar, North West Ethiopia. Science Journal of Public Health 2: 461-468. 